\title{
Religious Homogamy Affects the Connections of Personality and Marriage Qualities to Unforgiving Motives: Implications for Couple Therapy
}

\author{
Annabella Osei-Tutu ${ }^{1}\left(\mathbb{D}\right.$, Everett L. Worthington, Jr. ${ }^{2, *}{ }^{\circledR}$, Zhuo Job Chen $\left.{ }^{3}{ }^{(}\right)$, Stacey McElroy-Heltzel ${ }^{4}{ }^{(}$, \\ Don E. Davis ${ }^{5}$ and Melissa Washington-Nortey ${ }^{6}$ \\ 1 Department of Psychology, University of Ghana, Legon, Accra, Ghana; aopare-henaku@ug.edu.gh \\ 2 Department of Psychology, Virginia Commonwealth University, Richmond, VA 23284, USA \\ 3 Department of Psychology, Clemson University, Clemson, SC 29634, USA; zhuoc@clemson.edu \\ 4 Department of Psychological and Quantitative Foundations, University of Iowa, Iowa City, IA 52242, USA; \\ stacey-mcelroy-heltzel@uiowa.edu \\ 5 Department of Counseling and Psychological Services, Georgia State University, Atlanta, GA 30303, USA; \\ ddavis88@gsu.edu \\ 6 Department of Psychology, King's College London, Addison House, Guy's Campus, London SE1 1UL, UK; \\ washingtonnpm@vcu.edu \\ * Correspondence: eworth@vcu.edu
}

check for updates

Citation: Osei-Tutu, Annabella, Everett L. Worthington Jr., Zhuo Job Chen, Stacey McElroy-Heltzel, Don E. Davis, and Melissa Washington-Nortey. 2021. Religious Homogamy Affects the Connections of Personality and Marriage Qualities to Unforgiving Motives: Implications for Couple Therapy. Religions 12: 917. https:// doi.org/10.3390/rel12110917

Academic Editor: Hans Zollner

Received: 30 May 2021

Accepted: 17 October 2021

Published: 21 October 2021

Publisher's Note: MDPI stays neutral with regard to jurisdictional claims in published maps and institutional affiliations.

Copyright: (c) 2021 by the authors. Licensee MDPI, Basel, Switzerland. This article is an open access article distributed under the terms and conditions of the Creative Commons Attribution (CC BY) license (https:/ / creativecommons.org/licenses/by/ $4.0 /)$.
Abstract: In Ghana, collectivism holds people together in marital relationships, even if partners are religiously different. Married partners still hurt, betray, or offend each other and might develop avoidance or vengeful (i.e., unforgiving) motives. We investigated whether religious homogamy moderated connections of personality and marriage variables to unforgiving motives. Heterosexual married couples $(\mathrm{N}=176$ heterosexual married couples; $\mathrm{N}=352$ individuals; mean marriage duration 10.89 years) participated. Most identified as Christian (83.5\% males; $82.3 \%$ females) or Muslim (11.9\% males; $14.3 \%$ females). Couple religious homogamy was related directly to lower unforgiving motives. Religious homogamy did not moderate the connection between some personality variables (i.e., agreeableness and trait forgivingness) and unforgiving motives. Religiously unmatched couples tended to have greater unforgiveness at higher levels of neuroticism and lower forbearing, marital satisfaction, and marital commitment relative to religiously matched couples. One implication is that couple therapists need to assess partner neuroticism, marriage climate (i.e., satisfaction and commitment), and the general tendency to forbear when offended. Those can combine to produce unforgiving relationships, which might make progress in couple therapy improbable.

Keywords: religious homogamy; marriage; forgiveness; forbearance; marriage satisfaction; marriage commitment; neuroticism

\section{Introduction}

The purpose of this article is to reflect on how religious homogamy might affect couples mired in conflict. We investigated a non-clinical sample of heterosexual married couples in Ghana-most of whom were religiously committed. We sought to understand the degree that they forgave a partner's transgressions and discuss the implications of our findings for spiritually integrated couple therapists (SICTs). We extrapolated our findings from our non-clinical sample to make suggestions about how SICTs might deal with religiously homogamous and religiously different couples in couple therapy.

\subsection{Religious Homogamy and Forgiveness in Couples}

Research on the roles of religion in couple relationships has proceeded energetically in the USA and Europe (Roberson et al. 2017; Stanley et al. 2016). One theme that has emerged is the unique stressors couples may face when they do not agree on their religious 
beliefs, values, and practices. Before proceeding, it is important to clarify what we mean by religion: religion is the practice of engagement with the sacred within a community of like-minded and like-valued people regarding beliefs, values, and practices (Davis et al. 2015). Spirituality, on the other hand, is closeness of connection with what one holds to be sacred, and several categories of sacred objects include God and religious institutions, humanity, the environment, and the transcendent (Davis et al. 2015). For the purposes of this paper, we focus specifically on religious identity, given its distinct and central role in delineating the rituals and practices associated with marriage, gender roles, and forgiveness. In the present article, religious identity is defined as the major religion with which a respondent self-identifies.

If partners do disagree about their religion, how does that affect their relationship and their couple therapy? One way to determine the effects of religious homogamy on marriages and deduce implications for couple therapy, is to examine it in a collectivistic society that favors relationship commitment over divorce. Africa is unique in its strong endorsement of collectivism reinforced by commitment to tribal and religious value systems. Collectivistic values and religious systems can alter how people manifest and manage lasting conflicts.

Contrary to popular myths, it is not good communication, conflict management, or intimacy that causes marriages to succeed. Rather, good marriages are those that can form, maintain, improve, and repair the strong emotional bond between partners (Gottman and Gottman 2015). Thus, being able to forgive and not holding onto unforgiving-avoiding and vengeful-motives is crucial to marital success.

Based on prior work in Western samples, we expect that most religious individuals, regardless of religion, will value forgiveness (e.g., Rye et al. 2000) and potentially even feel social pressure to forgive. People in religious groups understand, practice, and reinforce forgiveness through the lens of their religious beliefs and practice (Davis et al. 2009, 2012). When couples belong to different religions, it may interfere with social structures designed to facilitate forgiveness (e.g., Curtis and Ellison 2002). Part of how cultural structures facilitate forgiveness is through coordination, so when couples belong to different religious groups, they may engage a way of working towards forgiveness that does not align with their partner's way of working towards forgiveness. Thus, in religiously heterogamous couples, the repair mechanisms of damaged emotional bonds through forgiveness might differ. That might increase the risk of conflict occurring and escalating, which would increase the risk of chronic unforgiveness.

When both partners are from the same religion (i.e., religious homogamy), the cultural structures of their religion may work as intended to facilitate forgiveness, which may help couples maintain low levels of conflict in a relationship and repair damage to the emotional bond when it occurs. They might have more common social identities and exhibit less initial bias in attributions towards their partner. For example, religious people have been found to develop less unforgiving motives toward religious in-group members than toward religious out-group members (Greer et al. 2014). Their similarity of religious orientation may provide resources that prevent (i.e., higher value alignment that reduces the potential for conflict) or repair (i.e., structures of the religious organization that curb selfishness, including beliefs and values as well as communal authority and pressure) conflict. Therefore, we hypothesize that religiously homogamous couples are less unforgiving of identified transgressions by the partner than are non-religiously homogamous couples.

\subsection{Our Choice of Sample}

Although investigations of forgiveness have spread to a global stage, only about 100 studies have taken place in Africa (for reviews, see Worthington and Cowden 2017; Worthington et al. 2020). Marriages in Africa are an important opportunity to study conflicts because a legal contract and strong cultural structures reinforce commitment to the relationship, even if the couple is engaged in high levels of conflict and partners are highly distressed. Unforgiveness may abound when couples are unhappy, but partners 
remain committed based on structural and cultural constraints. In Ghana, it is common for couples to develop high unforgiveness while still maintaining high commitment, which leads to dynamics of enemyship - the belief that one is stuck in a relationship with a malicious partner (Adams 2005).

Africa has another layer of social glue that may amplify enemyship-religion. Many African nations are religious. In fact, Ghana is especially attractive as a way of studying the effects of religion and collectivism on marriage because Ghana is ranked as the most religious country in the world (Central Intelligence Agency 2020; approximately 71.2\% Christian, 17.6\% Muslim; and 5.2\% indigenous religions; Ghana Statistical Service 2012). Accordingly, religious beliefs, values, and practices shared by Christianity and Islam strongly influence social norms (e.g., forgiveness, forbearance, or commitment; Rye et al. 2000) related to marriage commitment and management of conflict.

Ghana is a doubly promising place to study factors that influence conflict in couples because not only is it highly religious, but it is also religiously tolerant. Thus, many couples marry outside of their religion (non-homogamous marriages). Thus, Ghana is a unique place to study how religious culture (a strong marker of group identity) may influence forgiveness and whether results from Western samples tend to replicate cross-culturally. For example, in-group members tend to forgive each other more willingly than do out-group members (for a meta-analysis, see Van Tongeren et al. 2014).

In studies conducted among a selection of Christians in Ghana, Osei-Tutu et al. (2021) reported that engagements with different Christian church settings shaped understandings and expressions of love in the family context. A purpose of the present study is to explore how religious homogamy may affect how couples respond to and manage transgressions. The hope is that our findings can inform spiritually integrated couple therapy (SICT), which is couple therapy in which the couple therapist takes the religious beliefs, values, and practices of couples into account when applying therapeutic interventions. In individual psychotherapy, the psychotherapist must be attuned to the religious beliefs, values, and practices of the patient. But in couple therapy this can be more complex because partners can differ on their religious beliefs, values, and practices. Investigating the role of religious homogamy or heterogamy is important in SICT.

\subsection{Moderating Effects of Religious Homogamy between Personality and Unforgiving Motives}

In Western samples, research has found inconsistent relationships between religious homogamy and variables associated with personality, relationship satisfaction, and conflict management (Fincham et al. 2006), which may suggest that other moderators are influencing the results. In the present study, we examined several potential moderating effects based on prior theory and research on forgiveness.

We hypothesized that some personality qualities might affect the relationship between religious homogamy and unforgiving motives. The first potential moderating effect is on neuroticism. People high in neuroticism tend to perceive more hurts, feel more hurt after offenses, and then ruminate on them for longer, which all create a greater potential for stress and poor resolution of conflict (Hodge et al. 2020). Religious similarity might buffer the association of neuroticism on unforgiveness.

As a second possible moderating effect, we might advance similar reasoning for agreeableness, which is associated with people's tendencies to cooperate and engage in behaviors that tend to reduce offenses. Religious similarity may amplify the association of agreeableness and unforgiveness.

A third potential moderating effect we examined was trait forgivingness. Trait forgivingness has been modestly related to states of forgiveness (for a review, see Fehr et al. 2010). However, most of that research has examined people who were not married to each other. Marital dynamics provide strong cues that might overwhelm the effects of trait forgivingness. Thus, we tested whether religious homogamy might moderate the relationship between trait forgivingness and unforgiving motives. 


\subsection{Moderating Effects of Religious Homogamy between Qualities of the Marriage and Unforgiving Motives}

Marriages are systems (Herbine-Blank and Sweezy 2021) and might not be easily affected by personality variables unless the variables are very strong. However, qualities of the marriage-like one's willingness to make a soft response to a perceived transgression (see Gottman and Gottman 2015) might be vital in affecting how partners might or might not be unforgiving. Namely, if marital qualities set up a strong norm of the marriage of "softness" or of "harshness", they might be highly influential as to whether religious homogamy affects unforgiving motives. This is consistent with Gottman's theorizing on negative sentiment override, a phenomenon that occurs when marriages (or marriage-like relationships) become so overwhelmingly negative in affective tone that negative affect will overwhelm other factors (Hawkins et al. 2002).

\subsubsection{Responses to Offenses and Hurts as Qualities of a Marriage}

When partners are hurt or offended as is inevitable in any long-term romantic relationship, they respond. Habitual responses reveal an important quality of the marriage. Partners can retaliate, which often creates additional hurts and conflict and can, if it becomes habitual, mire the relationship in conflict. But soft responses promote relational healing. Several soft responses are possible: forbearance, acceptance, tolerance, minimization, and emotional suppression complement forgiveness as soft responses to offenses.

\subsubsection{Soft Responses Defined}

Forbearance is regulating the experience of and expression of negative emotions after conflict such that one makes a "soft" response by not responding with anger or confrontation. Forbearance is usually done for the good of the group or relationship, giving it a positive motivation. Forbearance is choosing not to respond negatively to provocations for the sake of harmony in the relationship, group, or collective.

Acceptance is an emotional response that calmly and intentionally refuses to react negatively to previously aggravating differences. Acceptance seeks to put aside the offense, relegating it so an experiential sphere of non-reactivity. Couple therapies often suggest that partners should change what they can and accept what they cannot change (Baucom et al. 2015; Christensen et al. 2015; Hayes et al. 2013). Forbearance is not exactly like acceptance.

Tolerance of offenses or injustices merely inhibits negative responses, putting up with them without negative behavioral response. When people tolerate offenses, they often inhibit their negative behavioral responses but continue to experience negative emotions.

Minimization of offenses is thinking something like this isn't very important. Minimizing might or might not be effective at emotional control. It tends to be less effective when the offense is very hurtful.

Emotional suppression is either consciously or unconsciously seeking to avoid the conscious experience of negative emotion. In Western, individualistic cultures, emotional suppression is positively associated with poor interpersonal functioning (Gross and Oliver 2003), relationship dissatisfaction, and increased thoughts about breaking up a romantic relationship (Impett et al. 2012).

\subsubsection{Soft Responses Contrasted with Forbearance}

In the current article, we seek to study forbearance, thus we contrast it with these aforementioned alternatives. Forbearance is not making a decision to forgive. Forbearance inhibits negative responses after a transgression, but it does not necessarily seek to treat the offender as a valued and valuable person as decisional forgiveness does. Nor does it seek to replace negative resentful, bitter, and unforgiving emotions and motivations as emotional forgiveness does. Furthermore, forbearance is driven by a desire for group harmony, but forgiveness might have many additional motivations.

Forbearance is similar to acceptance in producing emotional equanimity. They differ in that acceptance seeks to consign the offense to impermeability, but forbearance readily 
acknowledges that the offense occurred and that one has sought to inhibit responding for positive, group-relevant reasons. In addition, forbearance is likely more culturally determined and therefore less consciously intentional than is acceptance.

Forbearance is different from tolerance of an offense. Forbearance and tolerance both inhibit negative behavior in response to an offense. Forbearance produces more emotional equanimity than does tolerating an offense. Tolerance can lead to grudging resignation and teeth-gritting willful inhibition of responding.

Forbearance is different from minimizing. Whereas minimizing seeks to treat an offense as unimportant and to thus forget it, forbearance is seen as a moral act that accepts the reality of the offense and embraces that one is not responding negatively for the relationship's ultimate good.

Forbearance differs from emotional suppression. Emotional suppression thwarts the expression of negative emotion either intentionally or unconsciously. Generally, emotional expression is inhibited because it is unpleasant. Forbearance inhibits negative emotional expression for a social good and is aimed at benefiting either a relationship or an entire group rather than being focused on self-benefit.

\subsubsection{Forbearance in Collectivistic Cultures}

Forbearance seems to show different relationships with relational outcomes in collectivistic samples (e.g., such as China; Wei et al. 2012). A major difference then, between Western, independence-based cultures and collectivistic cultures is likely how frequently they use emotional suppression. In individualistic cultures, it is culturally dysphoric. In collectivistic cultures, forbearance is usually culturally congruent and does not seem to the person to be an effortful suppression of emotion. Many religions-including Christianity (e.g., "Forbearing one another, and forgiving one another, if any man have a quarrel against any: even as Christ forgave you, so also do ye"; Col. 3:13; KJV) also value forbearance.

1.4.5. Religious Homogamy as a Moderator between Forbearance and Marital Satisfaction and Commitment

In the present study, we examine marital forbearance, which is one's disposition to forbear harsh responses specifically for the sake of the marriage. Thus, based on some of this work, we expected that religious homogamy might moderate the relationship between marital forbearance and unforgiveness.

In romantic marital relationships, marital satisfaction and commitment can strongly affect whether people are motivated to forgive or to hold grudges. Berry and Worthington (2001) examined 39 married participants classified as either happy $(n=19)$ or unhappy $(n=20)$ with their relationship. When couples imagined a typical interaction with their partner, they reported more unforgiving responses if their marital quality was low than if it was high. We expected that people in a religiously discordant marriage might experience more avoidance at lower relationship quality. To manage conflict, couples may feel motivated to avoid it altogether.

\subsection{Study Hypotheses}

The purpose of the present study was first to examine the degree to which religious homogamy was related to greater unforgiving motives when partners were hurt or offended. We expected that not sharing a similar religious commitment would dilute the influence of religious structures that facilitate forgiveness, which might make it more likely that couples would adopt a stance of enemyship in which commitment may remain high, but forms of unforgiveness remain high. Thus, in Hypothesis 1, we predicted that couples who were religiously different would report higher avoidance and revenge motives than couples would who were religiously similar.

Next, we examined a series of potential moderating effects on personality and dispositional variables and their relationship to unforgiving motives. For each, we expected a similar pattern, in which religious homogamy would weaken the link between personality and unforgiving motives. We investigated neuroticism (Hypothesis 2a), agreeableness 
(Hypothesis 2b), and trait forgivingness (Hypothesis 2c) as predictors of unforgiving motives.

Finally, we examined the potential moderating effects of religious homogamy on stronger and weaker marriages. Those different marriage environments are operationalized in terms of marital forbearance (Hypothesis 3a), marital satisfaction (Hypothesis 3b), and marriage commitment (Hypothesis $3 \mathrm{c}$ ) as predictors of unforgiving motives.

\section{Materials and Methods}

\subsection{Participants}

A total of $\mathrm{N}=176$ heterosexual married couples $(\mathrm{N}=352$ individuals) participated in the study. Couples were married for an average of 10.89 years $(\mathrm{SD}=9.86$, range $=1-50)$ and had an average of 2.36 children ( $\mathrm{SD}=1.72$, range $=0-9)$. Male participants had an average age of 41.50 years $(\mathrm{SD}=11.37$, range $=21-73)$; female participants had an average age of 36.65 years $(\mathrm{SD}=10.32$, range $=19-73)$. In terms of ethnicity, $31.1 \%$ of male participants identified as Akan, $24.3 \%$ as Ewe, $22.6 \%$ as Ga-Dangme, $7.9 \%$ as Guan, $7.3 \%$ as another ethnicity, and $6.2 \%$ as Mole-Dagbani. For female participants, 39.4\% identified as Akan, $19.4 \%$ as Ewe, $16.6 \%$ as Ga-Dangme, $10.9 \%$ as Mole-Dagbani, $6.3 \%$ as Guan, and $5.7 \%$ as another ethnicity. Most (58.8\%) males had a tertiary level of education, while smaller numbers had a secondary level (31.1\%), basic level $(9.6 \%)$, or no formal education $(0.6 \%)$. Similarly, $50.9 \%$ of females had a tertiary level of education, while smaller numbers had a secondary level $(26.9 \%)$, basic level $(19.4 \%)$, or no formal education $(2.9 \%)$.

Males predominantly identified as Christian (83.6\%), followed by Muslim (11.9\%), Traditionalist $(2.8 \%)$, no religion $(1.1 \%)$, or another religion $(0.6 \%)$. Females also predominantly identified as Christian (82.3\%), followed by Muslim (14.3\%), Traditionalist (2.9\%), or no religion $(0.6 \%)$. Finally, $83.5 \%(\mathrm{n}=147)$ of couples were identified as having the same religion whereas $16.5 \%(n=29)$ reported different religions. In terms of specific pairings, the religiously homogamous couples were both Christian $(n=134)$. Some were both Muslim $(n=11)$ and both Traditionalist $(n=2)$. The non-homogamous couples were Christian/Muslim ( $n=20)$, Christian/Traditionalist $(n=3)$, Muslim/Traditionalist $(n=3)$, Christian/None $(n=2)$, and Christian/Other $(n=1)$.

\subsection{Measures}

\subsubsection{Demographic Items}

Participants completed a demographic questionnaire that asked about duration of marriage, number of children, gender, age, ethnicity, education, and religion.

\subsubsection{Religious Homogamy (i.e., Religious Similarity-Dissimilarity)}

We inspected demographic data to determine whether the couples were religiously different.

\subsubsection{Offense-Specific Unforgiveness}

The 12-item Transgression-Related Interpersonal Motivations scale (TRIM; McCullough et al. 1998) was used to measure recent marital offense-specific unforgiveness including a combination of avoidance (e.g., "I avoid him/her") and revenge (e.g., "I am going to get even"). Items are rated using a 5-point rating format ranging from $1=$ Strongly disagree to $5=$ Strongly agree. Higher scores represent higher levels of unforgiving motivations towards one's partner in response to an interpersonal offense. The scale has evidence supporting construct validity for interpreting its scores, being moderately and negatively related to relationship satisfaction $(r=-0.47)$ and empathy $(r=-0.80 ;$ McCullough et al. 1998). For the present study, the score on unforgiving motives was the criterion variable in all analyses. The alpha for unforgiving motives for men was 0.91 and for women was 0.92 . 


\subsubsection{Neuroticism and Agreeableness}

The 10-item Personality Inventory (Gosling et al. 2003) was used to measure the Big Five personality traits: neuroticism (e.g., "Anxious, easily upset") and agreeableness (e.g., "Sympathetic, warm"). Items are rated using a seven-point rating format ranging from 1 = strongly disagree to 7 = strongly agree. Higher scores represent higher levels of neuroticism and agreeableness. The subscales have evidence supporting construct validity of its scores, being related to the corresponding subscales of the Big Five Inventory (agreeableness $r=0.70$; neuroticism $r=0.81$ ). The subscale scores also demonstrated adequate estimated internal reliability (neuroticism $\alpha=0.73$; agreeableness $\alpha=0.40$; Gosling et al. 2003). For the present study, the neuroticism alpha for men was 0.64 and for women it was 0.62 ; the agreeableness alpha for men was 0.60 and for women it was 0.61 .

\subsubsection{Trait Forgivingness}

The 10-item Trait Forgivingness Scale (TFS; Berry et al. 2005) was used to measure trait forgivingness. Items (e.g., "I am a forgiving person") are rated using a five-point response format ranging from $1=$ strongly disagree to $5=$ strongly agree. Items are summed to form a full-scale score, where higher scores represent higher levels of dispositional forgivingness. The TFS has evidence supporting the construct validity of scores, being strongly and positively related to other trait measures of forgivingness $(r=0.50)$ and strongly and negatively related to rumination $(r=-0.69)$. In a previous study, the TFS also had estimated internal reliability of $\alpha=0.80$ (Berry et al. 2005). For the present study, the alpha for men was 0.82 and for women it was 0.79 .

\subsubsection{Marital Forbearance}

The four-item Group Harmony Index (Lin 2016) was adapted to measure marital forbearance. For the present study, the word "the group" was replaced by the word "my marriage" within the items. Items (e.g., "I try to control my expression of negative feelings for the sake of [my marriage]") are rated using a five-point rating format ranging from $1=$ strongly disagree to $5=$ strongly agree. Higher scores represent higher levels of marital forbearance. The scale has evidence supporting construct validity in interpreting its scores. African-American and Asian-American university students consistently scored higher than European-American students on forbearance for the sake of group harmony. In university students, religious "Nones" scored lower than mainline Protestant, Baptist, and Catholic university students, which scored equally to Hindus, Muslims, and Buddhists. The scale score also demonstrated adequate estimated internal reliability in the present study, the alpha for men being $=0.90$ and for women $=0.91$.

\subsubsection{Marriage Satisfaction}

The 5-item Quality of Marriage Index (QMI; Mitchell et al. 2015) was used to measure marital satisfaction. Items (e.g., "We have a good marriage.") are rated on a seven-point response format ranging from $1=\mathrm{I}$ do not agree at all to $7=\mathrm{I}$ perfectly agree. Items are summed to form a full-scale score, where higher scores represent higher levels of marital quality. The index has demonstrated evidence of construct validity, being strongly and positively related to relationship commitment $(r=0.62)$. In a previous study, the index also had estimated internal reliability of $\alpha=0.91$ (Mitchell et al. 2015). For the present study, alpha for men was 0.85 and for women was 0.63 .

\subsubsection{Marriage Commitment}

The seven-item commitment subscale of the Investment Model Scale (Rusbult et al. 1998) was used to measure marriage commitment. Items (e.g., "I am committed to maintaining my relationship with my partner.") are rated using a nine-point rating format ranging from $0=$ do not agree at all to $8=$ completely agree. Higher scores represent higher levels of marital commitment. The subscale has evidence supporting construct validity of its scores, being related to dyadic adjustment $(r=0.69$; Rusbult et al. 1998). The subscale scores also 
demonstrated adequate estimated internal reliability $(\alpha=0.91-0.95)$. For the current study, the alpha for men was 0.95 and for women it was 0.81 .

\subsection{Procedure}

Ethical approval for the study was issued by the Ethics Committee for the Humanities, University of Ghana. Data were collected between May and September 2017. Participants were recruited from the Greater Accra region of Ghana. Three research assistants administered the research questionnaires. They visited homes and workplaces in search of married individuals to participate in the study. Research assistants introduced themselves and the study indicating that they sought couples in which each partner would complete a questionnaire on forgiveness in their marriage. Married individuals who expressed an interest $(\mathrm{N}=200)$ solicited the participation of their partners. Four (4) married individuals dropped out because their partners did not want to take part in the study. Other prospective participants and partners $(n=20)$ were unavailable to complete the questionnaire even upon multiple follow-up attempts by the research assistants. Hence, a total of 176 couples completed the questionnaires. Questionnaires were administered to partners individually but simultaneously, upon completion of consent procedures. Research assistants clarified questions that arose, and they ensured that partners did not communicate about how to respond to the items on the questionnaire. The questionnaire was in English (Ghana's official language). The majority of the couples in the study had some level of formal education and could read and write English. A few participants who had no formal education but understood English were assisted by the research assistants with the reading of the questionnaire. Each participant received the equivalent of \$2(USD) upon completion of the questionnaire.

\section{Results}

Statistical analyses were computed using selected R packages (R Core Team 2017). Bivariate correlations indicated that age, number of years married, and number of children were not significantly related to any of the predictor or outcome variables for either men or women ( $\mathrm{r}$ ranged from -0.06 to 0.10 ). Therefore, these variables were not statistically controlled in our primary analyses. We reported means, standard deviations, and correlations among all study variables for men (above the diagonal) and women (below the diagonal) in Table 1. Men's and women's scores on the study variables were significantly correlated with two exceptions. Scores on women's personality variables (neuroticism, agreeableness, and trait forgivingness) did not correlate with their relationship scores; forbearance did. However, for men, scores on all four personality measures were correlated with scores on relationship variables.

Table 1. Descriptive Statistics and Intercorrelations of Variables for Men and Women.

\begin{tabular}{cccccccccc}
\hline & Unforgiveness & Neurotic & Agreeable & Forgiving & Forbear & Satisf & Commit & $M$ & SD \\
\hline Unforgiveness & - & 0.34 & -0.37 & -0.38 & -0.59 & -0.72 & -0.80 & 10.66 & 5.70 \\
Neuroticism & -0.02 & - & -0.79 & -0.62 & -0.23 & -0.36 & -0.32 & 6.35 & 3.19 \\
Agreeableness & -0.04 & -0.34 & - & 0.62 & 0.27 & 0.38 & 0.35 & 10.40 & 2.93 \\
Forgivingness & -0.09 & -0.56 & 0.13 & - & 0.21 & 0.42 & 0.38 & 37.05 & 8.10 \\
Forbearance & -0.51 & 0.08 & -0.11 & 0.02 & - & 0.37 & 0.58 & 14.94 & 4.41 \\
Satisfaction & -0.57 & 0.09 & -0.01 & 0.08 & 0.47 & - & 0.78 & 25.98 & 7.91 \\
Commitment & -0.77 & 0.11 & 0.03 & 0.11 & 0.56 & 0.64 & & 39.55 & 11.19 \\
$M$ & 11.15 & 6.21 & 10.86 & 37.82 & 15.08 & 26.36 & 39.37 & & \\
$S D$ & 6.23 & 2.75 & 7.60 & 7.31 & 4.59 & 9.38 & 11.01 & \\
\hline
\end{tabular}

Note. Correlations and descriptive statistics for men appear above the diagonal, and for women appear below the diagonal. Unforgiveness $=$ TRIM; Forgiveness $=$ Trait Forgiveness Sale; Satisfaction $=$ Quality of Marriage Index Commitment $=$ Marriage Commitment; Forbearance $=$ Group Harmony Index -4 . All correlations except italicized ones are significant at $p<0.01$. 


\subsection{Primary Analyses}

Given our data's dyadic nature, we employed multilevel modeling with random intercepts in order to control for lack of independence of observations. In this model, individuals (level 1) were nested within couples (level 2).

\subsubsection{Hypothesis $1-$ Homogamy on Unforgiving Motives}

As predicted, religious homogamy was significantly related to unforgiving motives $\left(b=-2.98, p=0.007, \eta^{2}=0.04\right)$. When an individual was in a religiously homogamous marriage, they experienced less avoidance and less revenge motivations than individuals in a religiously discordant marriage.

3.1.2. Hypothesis 2a-Homogamy Moderating the Relationship between Neuroticism and Unforgiving Motives

Homogamy significantly moderated the effect of neuroticism on unforgiving motives $\left(b=0.35, p=0.032, \eta^{2}=0.02\right)$. Contrary to hypotheses, within couples who were of a same religion, neuroticism was associated with unforgiving motives (simple slope test $b=0.28$, $t=3.01, p<0.001)$. However, within couples of the different religion, neuroticism did not influence unforgiveness.

3.1.3. Hypothesis $2 \mathrm{~b}-$ Homogamy Moderating the Relationship between Agreeableness and Unforgiving Motives

Homogamy did not significantly moderate the effect of agreeableness on unforgiving motives $\left(b=-0.12, p=0.432, \eta^{2}=0.00\right)$. Hypothesis $2 b$ was not supported.

3.1.4. Hypothesis $2 \mathrm{c}-$ Homogamy Moderating the Relationship between Trait Forgivingness and Unforgiving Motives

Homogamy did not significantly moderate the effect of trait forgivingness on unforgiving motives $\left(b=-0.10, p=0.154, \eta^{2}=0.01\right)$. Hypothesis $2 \mathrm{c}$ was not supported.

3.1.5. Hypothesis 3a-Homogamy Moderating the Relationship between Dispositional Marital Forbearance and Unforgiving Motives

Homogamy was a significant moderator for the effect of marital forbearance on unforgiving motives $\left(b=0.44, p=0.004, \eta^{2}=0.03\right)$. Supporting hypothesis $3 a$, regardless of whether couples were of the same or a different religion, individuals higher in forbearance experienced lower unforgiveness than those low in forbearance. However, there was a bigger discrepancy between religiously discordant couples and the religiously homogamous couples in revenge scores when marital forbearance was low. In other words, marital forbearance appeared to matter more for religiously discordant couples than for religiously homogamous couples.

3.1.6. Hypothesis $3 b-$ Homogamy Moderating the Relationship between Marital Satisfaction and Unforgiving Motives

Homogamy significantly moderated the effect of marital satisfaction on unforgiving motives $\left(b=0.44, p<0.001, \eta^{2}=0.12\right)$. Supporting hypothesis $3 b$, regardless of whether couples were of the same or a different religion, individuals higher in marital satisfaction experienced lower unforgiveness than those low in marital satisfaction. However, there was a bigger discrepancy between religiously discordant couples and the religiously homogamous couples when marital satisfaction was low. In other words, marital satisfaction appeared to matter more for religiously discordant couples than for religiously homogamous couples in affecting their unforgiving motives.

3.1.7. Hypothesis $3 c-$ Homogamy Moderating the Relationship between Relationship Marital Commitment and Unforgiving Motives

Homogamy was a marginally significant moderator for the effect of marital commitment on unforgiving motives $\left(b=0.09, p=0.060, \eta^{2}=0.02\right)$. Partially supporting 
hypothesis 3c, regardless of whether couples were of the same or a different religion, individuals higher in marital commitment experienced lower unforgiving motives than did those low in marital commitment. However, there was a bigger discrepancy between religiously discordant couples and the religiously homogamous couples when marital commitment was low. In other words, marital commitment appeared to matter more for religiously discordant couples than for religiously homogamous couples.

\section{Discussion}

We examined the effect of religious homogamy on couples' unforgiving responses in a sample of Ghanaian married couples. Religious homogamy has often been found to be associated with indicators of stronger marriages. However, the present study made contributions on several fronts. First, this is one of the first studies to examine whether religiously similar marital partners forgive differently from religiously dissimilar couples. Davis et al. (2009) suggested this possibility based on their research on religious similarity and forgiveness, but their research was with US couples whose religious commitment, in general, was low. In the present study, we examined people with completely different religious affiliations. Second, the present study took place in Ghana, which is highly religiously attuned and more collectivistic than the US. Third, this is the first study in a West African context that focuses on unforgiving motives in couples. We hypothesized and tested the effect of our predictor variables on unforgiving motives (i.e., the sum of avoidance and revenge motivations). Couples generally do not act on either avoidance or revenge motives, but the motives fuel ways they act toward each other in establishing, maintaining, growing, and repairing damaged emotional bonds. Emotional bonding is at the root of satisfied and stable couples (Gottman and Gottman 2015). Fourth, besides testing potential moderators between religious homogamy and unforgiving motives that are personality and marital-quality variables, we tested forbearance. Forbearance has been hypothesized to play a prominent role in the way that collectivistic societies deal with transgressions (Wei et al. 2012). We examined how marital forbearance affects forgiveness in couples.

The findings yield a new look at prior studies that have identified religious homogamy as a protective factor in marriage (see Heaton and Mitchell 2012; Schramm et al. 2012). First, we address process variables that prior studies have not addressed-unforgiveness and forbearance. The present study shows that religious homogamy is important when couples are dealing with transgressions in their marriage. It appears that identifying with a similar religion (i.e., Christian vs. Muslim) might foster the use of a similar religious orientation (i.e., intrinsic or extrinsic; Davis et al. 2009) or shared religious identity (i.e., both theologically conservative or progressive; Greer et al. 2014). This orientation is important in helping to coordinate how couples respond to transgressions within marriage. Couples with different religious orientations may rely on different (or even conflictual) lenses and have different expectations of each other when dealing with transgressions in a marriage. These differences may themselves become a source of conflict in the marriage.

The present study suggests a new look at religious homogamy as setting a positive backdrop for all marital interactions-within the highly religious Ghanaian culture. We found that when couples had different religions, a troubled relationship might become especially unforgiving. The dynamic of enemyship might contribute to the intensity of negative feelings, as partners see each other as untrustworthy but remain committed to staying in the relationship because of cultural constraints (Adams 2005). Religious homogamy seemed to tamper the impact of the troubled relationship and strengthened partners' willingness to forgive partner transgressions.

Second, the present study took place in Ghana, which is highly religiously attuned (Central Intelligence Agency 2020). If there is a place in the world where religious homogamy might be thought to make a difference, it is Ghana, which is strongly religious. As we suggested above, religious homogamy had detectable effects mostly when the rela- 
tionship was troubled. This corroborates the protective effects of religious homogamy in the face of partner offenses.

Third, although there have been almost 100 studies on forgiveness of individuals in Africa (for a review, see Worthington et al. 2020), this is the first study in a West African context that focuses on couples. We hypothesized and tested the effect of our predictor variables on avoidance and revenge motivations. Most past studies of religious homogamy have shown that religious homogamy affects marital satisfaction and commitment. In the present study, we found that religious homogamy moderated the relationships among relationship or personality variables and one's motives to forgive offenses within the relationship.

Fourth, we tested religious homogamy as a potential moderator between both personality and marriage-climate variables and unforgiving motives. As part of the marital climate, we tested marital forbearance. Forbearance has been hypothesized to play a prominent role in the way that collectivistic societies deal with transgressions (Wei et al. 2012). Wei and her collaborators examined forbearance in the People's Republic of China, where it operated generally as an alternative to forgiveness. In Ghana, with its strongly Christian presence and thus a value on forgiveness, however, marital forbearance- the willingness to dampen emotional distress when hurt or offended for the good of the marriage - was still important. Religious homogamy functioned as a moderator between forbearance and unforgiving motives. Forgiveness had not replaced forbearance in this mostly Christian sample. Marital forbearance impacted forgiveness, but generally only in religiously discordant couples. The religiously misaligned couples who were low in marital forbearance were much more likely to maintain unforgiving motives than were those who were religiously attuned.

\subsection{Limitations and Future Research Directions}

Several limitations call for circumspection in interpreting the findings. First, the sample involved in this study is not a representative sample of all married couples in Ghana. Neither is it representative of all people with Ghanaian ancestry. Second, there was a substantial imbalance in the prevalence of homogamous (83 percent) and heterogamous (only 17 percent) couples. This imbalance might have skewed some results. Third, although we did not assess it directly, some findings might be skewed by Ghana being more gender traditional than other cultures. That gender traditionalism could influence more attitudes toward complementarianism and less acceptance of egalitarianism, which could extend to traditional same-religious marriages. Third, most people married within their religion, but about one-fifth of the couples married someone of a different faith. Marrying outside of one's faith has become increasingly common in the West, and religion generally has become less important for many couples in the West relative to Ghana. Thus, based on these limitations, the findings in the present study should be cautiously generalized to Ghana, to Western societies, to non-religious Eastern societies like China, or to countries that are predominantly Muslim, Hindu, or Buddhist. We also undertook the study to learn more about spiritually integrated couple therapy because the Ghanaian context provided the opportunity to study over-sampled committed, religious couples relative to what would be available in the United States and Western Europe. Thus, these couples were not in couple therapy or psychotherapy, and thus generalizing to treatment populations should also require circumspection.

The study also raises interesting questions that can be the focus of future studies. We did not assess how levels of religiousness might affect the marriages. Another question we did not investigate is whether denominational homogamy was important in predicting unforgiveness responses in the couples. Finally, this is one of few studies that investigate forbearance, and the only available study to investigate forbearance as a disposition within the marriage. We found that marital forbearance does affect unforgiving motives, and more so for religiously heterogamous couples than those matched on religious affiliation. Marital forbearance is important to investigate regarding couples. Kiecolt-Glaser et al. 
(2003) had newly wedded couples engage in a discussion that they disagreed about. Their likelihood of divorce ten years later depended on the rate at which the wife's cortisol decreased during sleep. That is, often one member of the couple-most usually but not always the wife-regulated the emotional climate of the relationship (see also Gottman and Gottman 2015). Being able to let go of emotional engagement quickly after conflict was crucial to the marital commitment. Our findings suggest that religious homogamy might moderate couples' marital forbearance and their likelihood of holding onto unforgiving motives.

\subsection{Implications for Marriage Counselling and Psychotherapy}

Despite the many limitations, the findings from this present study show that religious homogamy and marital quality are important predictors of unforgiveness in some Ghanaian marriages. Positive marriage climate (i.e., forbearance, marital satisfaction, and marital commitment) as well as being engaged in a similar religion with a marital partner are associated with decreased revenge and avoidance responses in the event of a transgression in a marriage. Practitioners can draw on these findings when working with married people. It is thus essential to assess initial marital satisfaction and commitment (often by psychometrically well-supported questionnaires) and assess marital forbearance either using clinical interviews or Lin's (2016) instrument, adapted as we have in the present article, to evaluate the way partners might respond to the many transgressions that couples in therapy inflict on each other. Because transgressions are not wholly avoidable in marital relationships, couple therapists can help couples address them through improving their relationships - as virtually all couple therapies seek to do-but also through training couples in forbearance to build more forbearance into the relationship.

Religious differences might (or might not) exist in couples. Filter models of romantic attraction assume that people often discuss these differences, especially if they are primary in importance to one or both partners, and stark differences result in "filtering" the partner out from a deepening relationship. That said, clearly religious differences-even if contentious - do get past the "filter." So, many couples do have disagreement and sometimes conflict around religious differences, although these disagreements might not lead to conflict even though the different viewpoints are ensconced in partners' religious identities.

People might choose to tolerate the differences (i.e., put up with the differences even though negative emotion is retained), minimize the differences (i.e., thinking, it really is not that important), forbear making negative responses for the good of the relationship, or simply put the differences away through acceptance. SICT might or might not address the differences. Usually, unless there is active conflict in couple counseling regarding religious differences, the couple therapy will focus on other emotionally hot topics. All couples have multiple unresolved differences that they must live with through tolerance, minimization, forbearance, or acceptance, or through active discussion and (hopefully) arriving at some acceptable mutual agree-to-disagree decision.

Integrated behavioral couple therapy and ACT often seek to promote acceptance, which is a similar but not identical concept to the other ways of managing differences. Our findings suggest that this may be of particular importance when couples are religiously different in their religious beliefs, values, and behaviors. Furthermore, it is important for practitioners who work with couples to discuss couple's expectations about forgiveness. This is needed when couples belong to different religions and actively disagree about important issues that are affected by religious differences.

Couple therapists who offer SICT are almost always responsive to their clients, integrating religion into treatment only at the couple's request (Hook et al. 2014; Worthington et al.). SICT comes in several varieties (Worthington et al.). Some is clergy SICT, lay SICT, and professionals who identify explicitly as SICTs. Even among professionals, some approaches use minimal explicit mention of religion. That essentially allows couples to do their own integration. Worthington et al. also described a "baptized" secular approach, in which therapists incorporate their own theological understanding into a secular 
approach. Some SICTs use a clinical-scientist-created and -tested, evidence-based, wholecloth approach. Finally, some use a patch-work quilt incorporation of evidence-based mini-interventions into either a whole-cloth or "baptized" approach. Generally, when couples are religiously homogamous, they tend to be forgiving of offenses. But, when couples are low in religious homogamy, those high in forbearance, satisfaction, and commitment tend to be forgiving, but very troubled couples tend not to be naturally forgiving. That suggests that interventions to promote forgiveness might be called for.

\section{Conclusions}

We set out to investigate predictors of unforgiveness in Ghanaian couples who were either religiously homogamous or not. We found that, for couples similar in religion, being high in neuroticism and having high forbearance, satisfaction, and commitment predicted more forgiveness of offenses. However, being dissimilar in religion suggested that those high in neuroticism, low in marital forbearance, satisfaction, and commitment tended to be unforgiving.

Author Contributions: Conceptualization, A.O.-T., S.M.-H., D.E.D., and E.L.W.J.; methodology, A.O.-T., S.M.-H., D.E.D., and E.L.W.J.; software, Z.J.C.; validation, Z.J.C., S.M.-H., D.E.D., and E.L.W.J.; formal analysis, Z.J.C., E.L.W.J.; investigation, A.O.-T.; resources, A.O.-T. and E.L.W.J.; data curation, A.O.-T.; writing —original draft preparation, E.L.W.J.; writing—review and editing, A.O.-T., S.M.-H., D.E.D., Z.J.C., M.W.-N., and E.L.W.J.; visualization, Z.J.C.; supervision, E.L.W.J.; project administration, A.O.-T., M.W.-N., and E.L.W.J.; funding acquisition, E.L.W.J. and A.O.-T. All authors have read and agreed to the published version of the manuscript.

Funding: This research was funded by the Templeton World Charity Foundation, grant number TWCF0101/AB66.

Institutional Review Board Statement: The study was conducted according to the guidelines of the Declaration of Helsinki, and approved by the Ethics Committee for the Humanities of the University of Ghana (Reference ECH 127/15-16).

Informed Consent Statement: Informed consent was obtained from all subjects involved in the study.

Data Availability Statement: Data were collected locally and are available on request from Dr. Zhuo Chen at zhuoc@clemson.edu.

Acknowledgments: Portions of this project were made possible through the support of a grant from Templeton World Charity Foundation. The opinions expressed in this publication are those of the authors and do not necessarily reflect the views of Templeton World Charity Foundation.

Conflicts of Interest: The authors declare no conflict of interest.

\section{References}

Adams, Glen. 2005. The cultural grounding of personal relationship: Enemyship in North American and West African worlds. Journal of Personality and Social Psychology 88: 948-68. [CrossRef] [PubMed]

Baucom, Donald H., Norman B. Epstein, Jennifer S. Kirby, and Jaslean J. LaTaillade. 2015. Cognitive-behavioral couple therapy. In Clinical Handbook of Couple Therapy, 5th ed. Edited by Alan S. Gurman, Jay L. Lebow and Douglas K. Snyder. New York: Guilford Press, pp. 23-60.

Berry, Jack W., and Everett L. Worthington Jr. 2001. Forgivingness, relationship quality, stress while imagining relationship events, and physical and mental health. Journal of Counseling Psychology 48: 447-55. [CrossRef]

Berry, Jack W., Everett L. Worthington Jr., Lynn E. O'Connor, Les Parrott III, and Nathaniel G. Wade. 2005. Forgivingness, vengeful rumination, and affective traits. Journal of Personality 73: 183-225. [CrossRef]

Central Intelligence Agency. 2020. The World Factbook: Ghana; Washington, DC: Central Intelligence Agency. Available online: https: / / www.cia.gov/library/publications/the-world-factbook/geos/gh.html (accessed on 20 February 2021).

Christensen, Andrew, Sona Dimidjian, and Christopher R. Martell. 2015. Integrative behavioral couple therapy. In Clinical Handbook of Couple Therapy, 5th ed. Edited by Alan S. Gurman, Jay L. Lebow and Douglas K. Snyder. New York: Guilford Press, pp. 61-94.

Curtis, Kristen T., and Christopher G. Ellison. 2002. Religious heterogamy and marital conflict. Journal of Family Issues 23: 551-76. [CrossRef] 
Davis, Don E., Joshua N. Hook, Daryl R. Van Tongeren, Aubrey L. Gartner, and Everett L. Worthington Jr. 2012. Can religion promote virtue? A more stringent test of the model of relational spirituality and forgiveness. The International Journal for the Psychology of Religion 22: 252-66. [CrossRef]

Davis, Don E., Kenneth G. Rice, Joshua N. Hook, Daryl R. Van Tongeren, Cirleen DeBlaere, Elise Choe, and Everett L. Worthington Jr. 2015. Development of the Sources of Spirituality Scale. Journal of Counseling Psychology 62: 503-13. [CrossRef]

Davis, Don E., Everett L. Worthington Jr., Joshua N. Hook, Daryl R. Van Tongeren, Jeffrey D. Green, and David J. Jennings II. 2009. Relational spirituality and the development of the Similarity of the Offender's Spirituality (SOS) Scale. Psychology of Religion and Spirituality 1: 249-62. [CrossRef]

Fehr, Ryan, Michele J. Gelfand, and Monisha Nag. 2010. The road to forgiveness: A meta-analytic synthesis of its situational and dispositional correlates. Psychological Bulletin 136: 894-914. [CrossRef]

Fincham, Frank D., Julie Hall, and Steven R. H. Beach. 2006. Forgiveness in marriage: Current status and future directions. Family Relations 55: 415-27. [CrossRef]

Greer, Chelsea L., Everett L. Worthington Jr., Yin Lin, Caroline R. Lavelock, and Brandon J. Griffin. 2014. Efficacy of a self-directed forgiveness workbook for Christian victims of within-congregation offenders. Spirituality in Clinical Practice 1: 218. [CrossRef]

Ghana Statistical Service. 2012. 2010 Population and Housing Census: Summary REPORT of final Results. Accra: Sankofa Press Limited.

Gosling, Samuel D., Peter J. Rentfrow, and William B. Swann Jr. 2003. A very brief measure of the Big Five personality domains. Journal of Research in Personality 37: 504-28. [CrossRef]

Gottman, John Mordechai, and Julie Schwartz Gottman. 2015. Gottman couple therapy. In Clinical Handbook of Couple Therapy. Edited by Alan S. Gurman, Jay L. Lebow and Douglas K. Snyder. New York: Guilford Press.

Gross, James J., and John P. Oliver. 2003. Individual differences in two emotion regulation processes: Implications for affect, relationships, and wellbeing. Journal of Personality and Social Psychology 85: 348-62. [CrossRef]

Hawkins, Melissa W., Sybil Carrère, and John M. Gottman. 2002. Marital sentiment override: Does it influence couples' perceptions? Journal of Marriage and Family 64: 193-201. [CrossRef]

Hayes, Steven C., Kirk D. Strosahl, and Kelly G. Wilson. 2013. Acceptance and Commitment Therapy: The Process and Practice of Mindful Change, 2nd ed. New York: Guilford Press.

Heaton, Tim B., and Colter Mitchell. 2012. Changing intergroup boundaries in Brazilian marriages: 1991-2008. Journal of Comparative Family Studies 43: 461-82. [CrossRef]

Herbine-Blank, Toni, and Martha Sweezy. 2021. Internal Family Systems Couple Therapy Skills Manual: Healing Relationships with Intimacy from the Inside Out. Eau Claire: PESI Publishing.

Hodge, Adam, Laura Captari, David K. Mosher, Nelish Kodali, Joshua N. Hook, Don E. Davis, and Daryl R. Van Tongeren. 2020. Forgiveness and personality: A meta-analytic review. In Handbook of Forgiveness, 2nd ed. Edited by Everett L. Worthington Jr. and Nathaniel G. Wade. New York: Routledge, pp. 97-106.

Hook, Joshua N., Everett L. Worthington Jr., Don E. Davis, and David C. Atkins. 2014. Religion and couple therapy: Description and preliminary outcome data. Psychology of Religion and Spirituality 6: 94-101. [CrossRef]

Impett, Emily A., Aleksandr Kogan, Tammy English, Oliver John, Christopher Oveis, Amie M. Gordon, and Dacher Keltner. 2012. Suppression sours sacrifice: Emotional and relational costs of suppressing emotions in romantic relationships. Personality and Social Psychology Bulletin 38: 707-20. [CrossRef]

Kiecolt-Glaser, Janice K., Cynthia Bane, Ronald Glaser, and William B. Malarkey. 2003. Love marriage and divorce: Newlyweds' stress hormones foreshadow relationship changes. Journal of Consulting and Clinical Psychology 71: 313-17. [CrossRef]

Lin, Yin. 2016. Forbearance across culture. Dissertation Abstracts International: Section B: The Sciences and Engineering, 77(3-B(E)). Available online: https:// www.proquest.com/docview/1744826721?pq-origsite=gscholar\&fromopenview=true (accessed on 10 January 2021).

McCullough, Michael E., K. Chris Rachal, Steven J. Sandage, Everett L. Worthington Jr., Susan Wade Brown, and Terry L. Hight. 1998. Interpersonal forgiving in close relationships: II. Theoretical elaboration and measurement. Journal of Personality and Social Psychology 75: 1586-603. [CrossRef]

Mitchell, Joel C., Keith J. Edwards, Scott B. Hunt, and Paul Poelstra. 2015. Relational commitment as a mediator of religiousness to marital quality. Journal of Psychology and Theology 43: 263-71. [CrossRef]

Osei-Tutu, Annabella, Glenn Adams, Darlingtina Esiaka, Vivian A. Dzokoto, and Adjeiwa Akosua Affram. 2021. The modernity/coloniality of love: Individualist lifeways and charismatic Christianity in Ghanaian worlds. Journal of Social Issues, 1-26. [CrossRef]

R Core Team. 2017. R: A language and Environment for Statistical Computing. Vienna: R Foundation for Statistical Computing, Available online: https: / / www.R-project.org/ (accessed on 15 January 2021).

Roberson, Patricia N. E., Jerika Christine Norona, Jessica N. Fish, Spencer B. Olmstead, and Frank Fincham. 2017. Do differences matter? A typology of emerging adult romantic relationships. Journal of Social and Personal Relationships 34: 334-55. [CrossRef]

Rusbult, Caryl E., John M. Martz, and Christopher R. Agnew. 1998. The Investment Model Scale: Measuring commitment level, satisfaction level, quality of alternatives, and investment size. Personal Relationships 5: 357-91. [CrossRef] 
Rye, Mark S., Kenneth I. Pargament, Ali M. Amir, Guy L. Beck, Elliott N. Dorff, Charles Hallisey, Vasudha Narayanan, and James G. Williams. 2000. Religious perspectives on forgiveness. In Forgiveness: Theory, Research, and Practice. Edited by Michael E. McCullough, Kenneth I. Pargament and Carl E. Thoresen. New York: Guilford Press, pp. 17-40.

Schramm, David G., James P. Marshall, Victor W. Harris, and Thomas R. Lee. 2012. Religiosity, homogamy, and marital adjustment: An examination of newlyweds in first marriages and remarriages. Journal of Family Issues 33: 246-68. [CrossRef]

Stanley, Scott M., Galena K. Rhoades, Shelby B. Scott, Gretchen Kelmer, Howard J. Markman, and Frank D. Fincham. 2016. Asymmetrically committed relationships. Journal of Social and Personal Relationships 34: 1241-59. [CrossRef]

Van Tongeren, Daryl R., Jeni L. Burnette, Ernest O’Boyle, Everett L. Worthington Jr., and Donelson R. Forsyth. 2014. A meta-analysis of intergroup forgiveness. The Journal of Positive Psychology 9: 81-95. [CrossRef]

Wei, Meifen, Kelly Yu-Hsin Liao, Puncky Paul Heppner, Ruth Chu-Lien Chao, and Tsun-Yao Ku. 2012. Forbearance coping, identification with heritage culture, acculturative stress, and psychological distress among Chinese international students. Journal of Counseling Psychology 59: 97. [CrossRef]

Worthington, Everett L., Jr., and Richard G. Cowden. 2017. The psychology of forgiveness and its importance in South Africa. South African Journal of Psychology 47: 1-14. [CrossRef]

Worthington, Everett L., Jr., Camilla W. Nonterah, Shawn O. Utsey, Brandon J. Griffin, Caroline C. Carneal, Annabella Osei-Tutu, Richard G. Cowden, Athena Cairo, Basil J. Pillay, Katherine Kulick Kardio, and et al. 2020. Forgiveness research in Sub-Saharan Africa. In Handbook of Forgiveness, 2nd ed. Edited by Everett L. Worthington Jr. and Nathaniel G. Wade. New York: Routledge, pp. 223-33.

Worthington, Everett L., Jr., Jennifer S. Ripley, Zhuo Job Chen, Vanessa Kent, and Elizabeth Loewer. Forthcoming. Spiritually integrated couple therapy. In Handbook of Spiritually Integrated Psychotherapies. Edited by P. S. Richards, K. Allen and D. K. Judd. Washington: American Psychological Association. 